\title{
The burden and characteristics of peripheral arterial disease in patients undergoing amputation in Korle Bu Teaching Hospital, Accra, Ghana
}

\author{
Antoinette A.A. Bediako-Bowan ${ }^{1}$, George O. Adjei, ${ }^{2}$ Joe N. Clegg-Lamptey $^{1}$ and Simon B. \\ Naaeder ${ }^{1}$
}

Ghana Med J 2017; 51(3):108-114 DOI: http://dx.doi.org/10.4314/gmj.v51i3.3

\begin{abstract}
${ }^{1}$ Department of Surgery, School of Medicine and Dentistry, College of Health Sciences, University of Ghana Accra. ${ }^{2}$ Centre for Tropical Clinical Pharmacology and Therapeutic, School of Medicine and Dentistry, College of Health Sciences, University of Ghana, Accra, Ghana
\end{abstract}

Corresponding author: Dr Antoinette A.A Bediako - Bowan

E-mail: abediako-bowan@ug.edu.gh

Conflict of interest: None Declared

\section{SUMMARY}

Background: To determine the prevalence of Peripheral Arterial Disease (PAD) and associated risk factors in patients undergoing amputation at the Korle Bu Teaching Hospital (KBTH), Accra, Ghana.

Objectives: A cross- sectional study of all patients undergoing lower extremity amputation at the Department of Surgery, KBTH.

Materials: A coded questionnaire was used to ascertain risk factors for PAD. The Edinburgh Claudication Questionnaire was used to determine symptomatic PAD and a $5 \mathrm{mmHz}$ hand held Summit ${ }^{\circledR}$ Doppler together with an Accoson ${ }^{\circledR}$ sphygmomanometer was used to determine PAD and its severity.

Method: Clinical diagnosis of symptomatic PAD was made using a symptom-based questionnaire and signs of PAD determined by measuring the ankle brachial pressure index (ABPI) by means of a handheld Doppler and sphygmomanometer. Risk factors were determined using the coded questionnaire and related to the occurrence and severity of PAD.

Results: The prevalence of PAD among recruited participants was $71 \%$. Twenty-eight per cent of participants with PAD in the index limb also showed signs of PAD in the other limb. The diagnosis of PAD was made in $71 \%$, using $\mathrm{ABPI}$, and 13\%, using ECQ. Twenty-seven per cent of patient with hypertension, seventeen per cent with diabetes and all patients with hypercholesterolemia were not on any form of medication.

Conclusion: There is a high prevalence of PAD among patients undergoing lower extremity amputation at the KBTH. The majority of PAD patients presented with moderate to severe PAD. Instituting measures to identify and control risk factors of PAD may reduce this high burden.

Funding: Not declared

Keywords: Peripheral arterial disease, ABPI, Prevalence, Ghana, Amputation

Funding source: Authors funded the study

\section{INTRODUCTION}

Peripheral arterial disease (PAD) is an atherothrombotic syndrome marked by stenosis and occlusion of peripheral arterial beds. The target organs are the brain, heart, intestine, kidneys and the limbs, typically the lower extremities.

It affects $12-14 \%$ of the general population and the prevalence is age dependent. ${ }^{1-3}$ Within one year of presentation with severe leg ischemia, 30\% of patients undergo a major amputation and $25 \%$ die of PAD. ${ }^{4}$ Globally, a majority of patients are asymptomatic and undiagnosed until the disease has progressed to a late stage, requiring limb amputation. Worldwide, the preva- lence of asymptomatic PAD ranges between 3-10\% and that of symptomatic PAD is $3 \%$ for patients in their $40 \mathrm{~s}$ and $6 \%$ for patients in their $60 \mathrm{~s} .{ }^{4}$ Symptoms range from intermittent claudication and leg numbness to ischemia requiring amputations. However, given the large number of asymptomatic PAD, clinical history has a low sensitivity for determining the presence of PAD. Risk factors for development and progression of PAD include smoking, hypertension, diabetes, hypercholesterolemia and physical inactivity. Successful treatment strategies of PAD include risk factor modification such as cessation of smoking and initiation of regular exercise, control of diabetes and hypercholesterolemia and 


\section{Original Article}

use of antiplatelet agents to reduce risk of atherothrombotic events. $^{5-8}$

Vascular disease accounts for $8.6 \%$ of major amputation after diabetic foot complications $(41.9 \%)$ and trauma $(38.4 \%){ }^{9}$ In patients with critical limb ischemia who do not have revascularization options, major amputation is required within 1 year in as many as $40 \%$ of patients. ${ }^{10}$ There has been a wide variation in reports of the prevalence of PAD from Sub-Saharan Africa. The prevalence has ranged from a low $1.7 \%$ in Central Africa to a high $28 \%$ in Dakar. ${ }^{7}$ Previous studies from Ghana have reported a PAD prevalence of $1 \% .^{12}$

There is an apparent lack of interventional procedures for patients with PAD in developing countries, and in many instances, the disease progresses to limb ischemia requiring amputation. The social and economic implications for patients who have amputations in the developing countries are enormous. The lack of adequate rehabilitation facilities and poor prosthetic services implies that amputees are often discharged from hospital with no programs for re-training. The cost of prostheses is also beyond the means of most patients who have undergone amputation in local hospitals and as such many of them are condemned to a wheelchair, crutches or are bed-ridden at home. ${ }^{13}$

Despite the recognition of PAD as a major thrombotic risk factor, its occurrence and burden are not sufficiently appreciated by clinicians, and most cases are undiagnosed. Increased awareness about PAD and benefits of risk factor reduction could potentially lead to a decrease in the disease burden. There is a paucity of data on the prevalence or incidence of PAD in Korle Bu Teaching Hospital (KBTH) and institutional protocols for treatment of PAD are lacking. This study determined the prevalence and severity of PAD and the associated risk factors in patients undergoing amputation at the KBTH. The study also evaluated the use of ankle brachial pressure index (ABPI) in the diagnosis of PAD.

\section{METHODS}

This was a cross-sectional study in the Department of Surgery in Korle $\mathrm{Bu}$ Teaching Hospital. The Korle $\mathrm{Bu}$ Teaching Hospital is the leading referral centre in Ghana and the third largest hospital in Africa. It has over 2000 beds, 21 clinical and diagnostic departments and an average daily attendance of 1500 patients with about 250 admissions. ${ }^{14}$ All patients undergoing lower extremity amputation from September 2013 to August 2014, were enrolled with the study. At the end of each day, patients admitted for amputation on each of the general surgical wards were recruited and their diagnosis and the procedures they were to undergo was confirmed by the Principal Investigator. The rationale for the study was explained in detail to the patients and an informed written consent was obtained.

A coded questionnaire was administered to consenting patients. The questionnaire sought to obtain information on demographic characteristics, reason for amputation, relevant clinical information including history of previous amputations and assess risk factors of PAD. The Edinburgh Claudication Questionnaire ${ }^{15}$ was used to diagnose symptomatic PAD. The ABPI was measured using a 5 millimeter Hertz $(\mathrm{mmHz})$ hand held Summit ${ }^{\circledR}$ Doppler to obtain systolic pressures in both right and left brachial and posterior tibial arteries. Each systolic pressure was measured twice, with an $A \operatorname{ccoson}{ }^{\circledR}$ sphygmomanometer (AC Cossor \& Son (Surgical) Ltd, Harlow, Essex CM19, 5QP). The ABPI was calculated by dividing the mean posterior tibial pressure in each leg by the mean of the brachial pressures. Their blood pressures were measured using an Accoson ${ }^{\circledR}$ sphygmomanometer and recorded in millimetres of mercury $(\mathrm{mmHg})$.

Peripheral arterial disease and its severity was defined using the American Diabetes Association consensus paper which quotes $0.91-1.3$ as the normal range of ABPI. ${ }^{16}$ Mild PAD have ABPIs of 0.7-0.9, moderate PAD range between 0.41 and 0.69 and ratios of less than or equal to 0.4 are quoted for severe disease. The fasting blood sugar of each subject was measured using a Contour $^{\circledR}$ glucometer and Contour ${ }^{\mathbb{B}}$ blood glucose test strips (Bayer Healthcare LLC, Mishawaka IN 46544, USA) and recorded in grams per decilitre ( $\mathrm{g} / \mathrm{dl})$.

Blood samples (5mls) were drawn at $6 \mathrm{am}$, after 8 hours of overnight fast, from all subjects to assess their lipid profile. The lipid profile was determined by means of an automated clinical chemistry analyser (Rz Monza Randox Laboratories Ltd UK). Lipid profile was recorded in millimoles per litre $(\mathrm{mmol} / \mathrm{L})$.

Stata, version 13 was used to analyse the data. Descriptive statistics were determined for all quantitative variables. Cross tabulation of continuous variables and association tests for data was analysed using correlation analysis. Regression analysis was used to investigate relationship between PAD and risk factors. The level of significance used was 0.05 . Ethical approval was sort from the Ethical and Review Committee of the School of Medicine and Dentistry, University of Ghana (Protocol Identification Number: MS-Et/M.7 - P 4.8/201213).All participants signed a written informed consent before enrolment into the study. 


\section{RESULTS}

A total of 76 patients were recruited over the period with a mean age of 65years. Forty-seven per cent (36) of patients were elderly (age $>65$ ) with a female: male ratio of $1.45: 1$. Thirty-six $(47.4 \%)$ patients were admitted for amputation on account of a wet gangrene whilst forty $(52.6 \%)$ were due to dry gangrene of the affected leg (Table 1). Other baseline demographic parameters of recruited participants are summarized in Table 1. Forty $(52.6 \%)$ patients were known hypertensive (Table 1). Eleven $(27.5 \%)$ of these patients were not on any form of medication and one patient had had a cerebrovascular accident 20 years earlier. The systolic blood pressures measured was higher than $140 \mathrm{mmHg}$ in 35 participants, 14 of whom were not known to be hypertensive.

Fifty-seven $(75 \%)$ of the patients were known diabetic (Table 1), 10 (17.5\%) of whom were not on any form of medication. The fasting blood sugars were above the upper limit of $6.0 \mathrm{mmol} / \mathrm{L}$ in $48(84.2 \%)$ patients who were known diabetics. Thirty-nine $(51 \%)$ of the patients were known to be both hypertensive and diabetic. Five (6.6\%) patients had been previously diagnosed with hypercholesterolemia and were on lipid lowering drugs. From the lipid profiles, seven $(9.2 \%)$ had hypercholesterolemia, but none were on lipid lowering drugs.
Using the Edinburgh Claudication Questionnaire (ECQ), 14 (18\%) patients were diagnosed with PAD, 34 (45\%) patients had no PAD symptoms and symptoms could not be assessed for 28 (37\%) patients because they were unable to walk because of a previous cerebrovascular accident, previous amputation or were generally weak due to old age (Table 2).

Using the ABPI, fifty-four (71\%) patients were diagnosed with PAD of the index limb (Table 2). Of these, $32(59.3 \%), 12(22.2 \%)$, and $10(18.5 \%)$ patients had severe, moderate and mild PAD, respectively. PAD of the index limb could not be assessed in 1 patient admitted for an above knee amputation because he had had previous below knee amputation.

Using the ABPI, 21 (28\%) patients already showed signs of PAD of the other lower limb (Table 2): 5 with moderate disease and 16 with mild disease. Of the patients diagnosed with PAD, 29 (53.7\%) were hypertensive, $39(72.2 \%)$ patients had diabetes and $5(9.3 \%)$ had hypercholesterolemia. Seven patients had high triglyceride levels, 5 had high HDL levels, 34 had low levels of HDL and 8 patients had high LDL levels. Ten (18.5\%) of these patients smoked and only $15(27.8 \%)$ exercised (Table 1).

Table 1 Baseline characteristics and Factors affecting Peripheral Arterial Disease

\begin{tabular}{|c|c|c|c|c|c|}
\hline Characteristics/Factor & $\begin{array}{l}\text { Number } \\
(\%) \\
(\mathrm{N}=76)\end{array}$ & $\begin{array}{l}\text { Number with Peripheral } \\
\text { Arterial Disease (\%) } \\
(\mathrm{n}-54)\end{array}$ & $\begin{array}{l}\text { Severity } \\
\text { Mild (\%) } \\
(0.7-0.9) \\
\mathrm{N}=10\end{array}$ & $\begin{array}{l}\text { f Peripheral A } \\
\text { Moderate }(\% \\
(0.4-0.69) \\
\mathrm{N}=12\end{array}$ & $\begin{array}{c}\text { rterial Disease } \\
\text { Severe }(\%) \\
(0.0 .4) \\
\mathrm{N}=32\end{array}$ \\
\hline $\begin{array}{l}\text { Age* } \\
>65 \\
45-64 \\
20-44 \\
\end{array}$ & $\begin{array}{l}36(47.4) \\
30(39.5) \\
8(10.5) \\
\end{array}$ & $\begin{array}{l}29(53.7) \\
20(37.0) \\
5(9.2)\end{array}$ & $\begin{array}{l}5 \\
2 \\
3\end{array}$ & $\begin{array}{l}6 \\
6 \\
0\end{array}$ & $\begin{array}{c}18 \\
12 \\
2\end{array}$ \\
\hline $\begin{array}{l}\text { Gender } \\
\text { Male(30) } \\
\text { Female(45) }\end{array}$ & $\begin{array}{l}30(39.5) \\
46(60.5)\end{array}$ & $\begin{array}{l}20(37.0) \\
34(63.0)\end{array}$ & $\begin{array}{l}4 \\
6\end{array}$ & $\begin{array}{l}3 \\
9\end{array}$ & $\begin{array}{l}13 \\
19\end{array}$ \\
\hline $\begin{array}{l}\text { Educational level } \\
\text { None } \\
\text { Primary level } \\
\text { Secondary level \& above }\end{array}$ & $\begin{array}{l}14(18.4) \\
27(35.5) \\
35(46.1)\end{array}$ & $\begin{array}{l}9(16.7) \\
22(40.7) \\
23(42.6)\end{array}$ & $\begin{array}{l}1 \\
1 \\
8\end{array}$ & $\begin{array}{l}1 \\
8 \\
3\end{array}$ & $\begin{array}{l}7 \\
13 \\
12\end{array}$ \\
\hline Diabetes mellitus & $57(75)$ & $39(72.2)$ & 9 & 10 & 20 \\
\hline Hypertension & $40(52.6)$ & $29(53.7)$ & 4 & 6 & 19 \\
\hline Hyperlipidemia & $5(6.6)$ & $5(9.3)$ & 3 & 1 & 1 \\
\hline Smoking & $12(15.8)$ & $10(18.5)$ & 2 & 1 & 7 \\
\hline Exercise & $23(30.3)$ & $15(27.8)$ & 3 & 4 & 8 \\
\hline $\begin{array}{l}\text { Awareness of reason for amputation } \\
\text { Yes } \\
\text { no }\end{array}$ & $\begin{array}{l}73(96.1) \\
3(3.9)\end{array}$ & $\begin{array}{l}51(94.4) \\
3(5.6)\end{array}$ & $\begin{array}{r}10 \\
-\end{array}$ & $\begin{array}{r}12 \\
-\end{array}$ & $\begin{array}{r}29 \\
3 \\
\end{array}$ \\
\hline $\begin{array}{l}\text { Reason for amputation } \\
\text { Wet gangrene } \\
\text { Dry gangrene }\end{array}$ & $\begin{array}{l}36(47.4) \\
40(52.6)\end{array}$ & $\begin{array}{l}20(37.04) \\
34(62.96)\end{array}$ & $\begin{array}{l}9 \\
1\end{array}$ & $\begin{array}{l}5 \\
7\end{array}$ & $\begin{array}{l}6 \\
26\end{array}$ \\
\hline $\begin{array}{l}\text { Type of amputation } \\
\text { Above knee } \\
\text { Below knee } \\
\text { Mid foot } \\
\text { Ray amputation }\end{array}$ & $\begin{array}{l}35(46.1) \\
29(38.2) \\
1(1.3) \\
11(14.4)\end{array}$ & $\begin{array}{l}28(51.9) \\
18(33.3) \\
0(0) \\
8(14.8)\end{array}$ & $\begin{array}{l}5 \\
2 \\
- \\
3\end{array}$ & $\begin{array}{l}3 \\
6 \\
- \\
3\end{array}$ & $\begin{array}{l}20 \\
10 \\
- \\
2\end{array}$ \\
\hline
\end{tabular}

*Age of two(2) participants was not recorded. 
Table 2 Presence of PAD using Edinburgh claudication questionnaire (ECQ) or Ankle Brachial Pressure Index (ABPI)

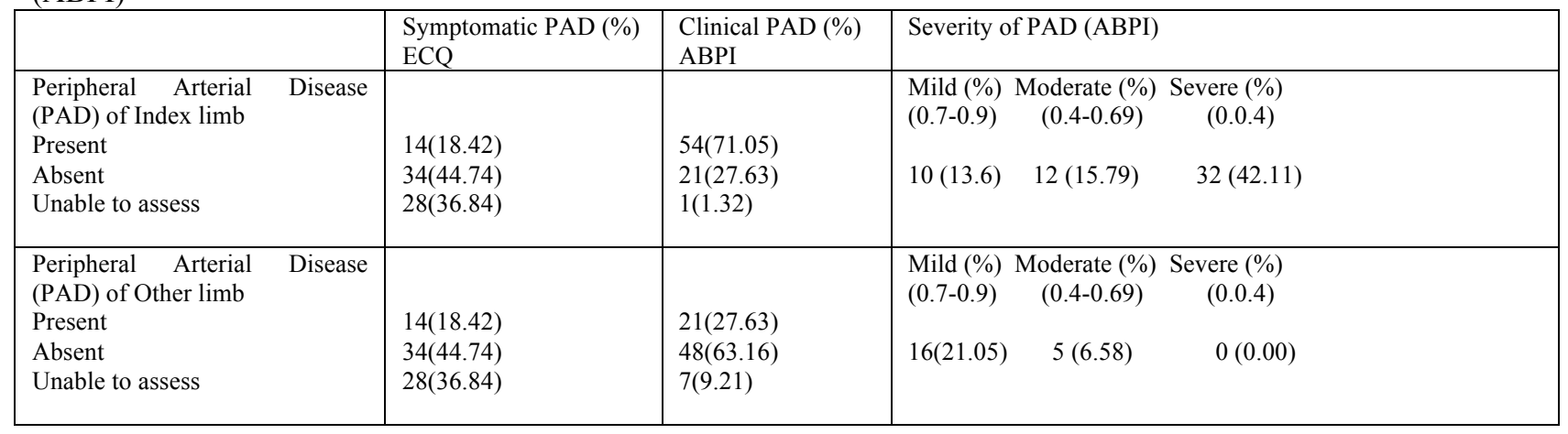

Univariate and multivariate analysis of the baseline demographic and clinical characteristics of the patients including age, gender, diabetes, hypertension, hypercholesterolemia, smoking and exercising showed no relationship with PAD (OR $>1$ for all comparisons) (Table $3)$.

Table 3 Measured values of selected clinical and lboratory parameters for patients undergoing lower limb amputation in KBTH.

\begin{tabular}{|l|l|}
\hline Variable & Result \\
\hline ABPI; Index limb, mean (sd) & $0.54(0.46)$ \\
\hline ABPI; Other limb, mean (sd) & $1.00(0.29)$ \\
\hline Systolic BP in mmHg, median (range) & $136(100-180)$ \\
\hline FBS, median (range) & $7.4(2.72-22.6)$ \\
\hline Serum cholesterol, median (range) & $2.94(0.23-19.83)$ \\
\hline Triglycerides, mean (sd) & $1.42(0.73)$ \\
\hline HDL, median (range) & $0.84(0.06-10.07)$ \\
\hline LDL, median (range) & $1.59(0.00-8.41)$ \\
\hline VLDL, median (range) & $0.55(0.51-5.00)$ \\
\hline Coronary Risk, median (range) & $0.44(0.00-121.29)$ \\
\hline
\end{tabular}

\section{DISCUSSION}

The prevalence of peripheral arterial disease in patients undergoing lower limb amputation in KBTH (71.1\%) was high. The high prevalence rate in this study is due to the subject population of patients undergoing amputation. Limb salvage procedures, which are almost nonexistent in our facility, attempted before admission for amputation was captured in this study. The lack of sophisticated methods of diagnosis and treatment in Ghana, lack of awareness of our people and late presentation means that many limbs that could be salvaged will continue to be lost. ${ }^{13}$ The Edinburgh Claudication Questionnaire $^{15}$ was used to diagnose symptomatic PAD. However, ninety per cent $(90 \%)$ of patients with asymptomatic PAD would be missed if a complaint of intermittent claudication was to be used in diagnosis. ${ }^{17,}{ }^{18}$ In this study, only $18.4 \%$ (14) of patients were diagnosed with PAD using the ECQ, thus missing the diagnosis in $39.5 \%$ (30) of the patients.
ABPI is considered a reliable method for diagnosing symptomatic and non-symptomatic PAD. ${ }^{19,}{ }^{20}$ Seventyone per cent (54) of patients were diagnosed with PAD using the ABPI in this study. The American Diabetes Association consensus paper quotes $0.91-1.3$ as the normal range of ABPI. ${ }^{16}$ This same consensus paper states that patients with mild disease have ABPIs of 0.70.9 , whilst those with moderate ischemia have ratios of between 0.41 and 0.69 . Patients with mild or moderate disease will be claudicants. Ratios of less than or equal to 0.4 are quoted for severe disease, and affected patients present clinically with critical limb ischemia.

A worrying trend noted in this study was that, of the forty patients who were known to be hypertensive, $27.5 \%$ were not on any form of medication. Also $17.5 \%$ of patients known to have diabetes were not on any form of medication and none of the patients with lipid profiles indicating hypercholesterolemia were on lipid lowering drugs. Controlling hypertension adequately reduces cardiovascular mortality in persons with PAD. ${ }^{21}$ and treatment of dyslipidaemia with statins has been documented to reduce the incidence of mortality, cardiovascular events and stroke in persons with PAD. ${ }^{7,22-24}$ Statins significantly reduce the incidence of intermittent claudication by $35 \% .^{7}$ Elderly persons with PAD and hypercholesterolemia should be treated with statins to reduce cardiovascular mortality and morbidity and progression of $\mathrm{PAD}^{7,22-25}$ and to improve exercise time until claudication.

Risk factor modification such as cessation of smoking and initiation of regular exercise reduces the risk of atherothrombotic events. Continuing smoking increases risk of amputation in patients with intermittent claudication. ${ }^{6}$ Cessation of smoking decreases progression of PAD to critical leg ischemia. ${ }^{5}$ The low rate of smoking recorded among patients in this study is consistent with the reported low prevalence of smoking in Ghana ${ }^{26}$ Ten $(83 \%)$ of the patients who smoked had PAD. 
Only 30\% (23) of the patients engaged in some form of exercise. However, $15(65 \%)$ of the exercising group had PAD. Walking exercise in patients with PAD prolongs the onset of claudication pain thus allowing the patient to walk longer but does not change the ABPI. ${ }^{27-}$ ${ }^{29}$ Supervised exercised training is recommended for a minimum of $30-45$ minutes in sessions performed at least three times per week for a minimum of 12 weeks and preferably for six months or longer. ${ }^{30,31}$ Strength training is less effective than treadmill walking. ${ }^{32}$ The lack of association between these known risk factors and PAD in this study could be due to to lack of statistical power or dilution of effect since the majority of diagnosed PAD was moderate-to-severe and the incidence of diabetes and hypertension were high.".Twenty-eight per cent of patients already showed signs of peripheral arterial disease of the other lower limb. Steps can be taken to halt or drastically reduce the progress rate of PAD in these patients such as controlling diabetes, hypertension, hypercholesterolemia as well as cessation of smoking, even in the low number of participants engaging in this risk factor and also encouraging exercises.

Endovascular approach is advocated in all $\mathrm{PAD}^{33}$ and could have been considered in our patients especially those who had mild and moderate PAD instead of amputation. Endovascular interventions in patients with chronic limb ischemia can result in limb salvage though they have a high likelihood of repeat interventions to maintain patency. ${ }^{34}$ Indications for lower extremity intraluminal angioplasty, endarterectomy or bypass surgery are (1) incapacitating claudication in persons interfering with work or lifestyle, (2) limb salvage in persons with limb-threatening ischemia as manifested by rest pain, non-healing ulcers, and/or gangrene and (3) vasculogenic impotence. ${ }^{35}$

Percutaneous balloon angioplasty and/or stenting is indicated for short-segment stenosis, whereas multisegment disease and occlusions are most effectively treated with surgical revascularization. ${ }^{36}$ Revascularization should be considered to improve symptoms of patients with intermittent claudication ${ }^{31}$ and should be considered in our patients who are showing signs of peripheral arterial disease in their other limb. Increased awareness among members of our health care community about the prevalence of peripheral arterial disease and benefits associated with risk-factor reduction should produce substantial decrease in the burden of this disease. Intensive educational programs are needed to educate physicians to use lipid lowering therapy in elderly persons with cardiovascular disease and dyslipidaemia. $^{37}$

\section{CONCLUSION}

There is a high prevalence of PAD among patients undergoing lower extremity amputation at the KBTH, majority presenting with moderate to severe PAD. The ECQ may not be the best tool to adapt to diagnose early PAD in our part of the world hence periodically measuring the ABPI of patients at risk of PAD may be better with early diagnosis of PAD. Further studies are suggested in a more general population to find the prevalence of PAD.

\section{ACKNOWLEDGEMENT}

We acknowledge the contributions made by the residents of the Department of Surgery of Korle Bu Teaching Hospital, Accra, Ghana, Mr Edmund Tetteh Nartey and the laboratory staff of the Centre for Tropical Clinical Pharmacology and Therapeutics.

\section{REFERENCES}

1. Criqui MH, Fronek A, Barrett-Connor E et al. The Prevalence of peripheral arterial disease in a defined population. Circulation 1985; 71(3): 510-515

2. Criqui MH. Peripheral arterial diseaseepidemiological aspects. Vasc. Med 2001; 6(3 suppl): 3-7

3. Selvin E, Erlinger TP. Prevalance of and risk factors for peripheral arterial disease in the United States: results from National Health and Nutrition Examination Survey 1999-2000. Circulation. 2004; 110: 738-743.

4. Norgren L, Hiatt WR, Dormandy JA, et al. Intersociety consensus for management of peripheral arterial disease. J Vasc surg, 2007: 45(suppl s) s5-s67.

5. Quick CRG, Cotton LT. The measured effect of stopping smoking on intermittent claudication. $\mathrm{Br} J$ Surg 1982; 69 (Suppl): S24-S26.

6. Juergens IL, Barker NW, Hines EA. Arteriosclerosis of veterans: a review of 520 cases with special reference to pathogenic and prognostic factors. Circulation 1960; 21: 188-199.

7. Pedersen TR, Kjekshus J, Pyorala K, et al. Effect of simvastatin on ischemic signs and symptoms in the Scandinavian Simvastatin Survival Study (4S). Am J Cardiol 1998; 81: 333-336

8. Mehler PS, Coll JR, Estacio R, Esler A, Schrier RW, Hiatt WR. Intensive blood pressure control reduces the risk of cardiovascular events in patients with peripheral arterial disease and type 2 diabetes. Circulation 2003; 107: 753-756.

9. Chalya PL, Mabula JB, Dass RM, et al. Major limb amputations: a tertiary hospital experience in northwestern Tanzania. J Orthop Surg Res 2012 May 11; 7: 18. Epub 2012 May 11 


\section{Original Article}

10. Powell RJ. Update on clinical trials evaluating the effect of biologic therapy in patients with critical limb ischemia. J Vasc 2012 Jul:56(1): 264-266

11. Kengne AP, Amoah AGB, Mbanya JC. Cardiovascular complications of diabetes mellitus in SubSaharan Africa. Circulation 2005; 112: 3592 3601

12. Akpalu J, Akpalu A, Ofei F. The metabolic syndrome among patients with cardiovascular disease in Accra, Ghana. Ghana Med J. 2011 Dec; 45(4):164-166

13. Naaeder SB. Amputation of the lower limb in Korle Bu Teaching Hospital, Accra. West Afr J Med 1993 Jan-Mar, 12(1): 21-26.

14. Korle $\mathrm{Bu}$ Teaching hospital; brief history. http://kbth.gov.gh/18/19html

15. Leng G, Fowkes F. The Edinburgh claudication questionnaire: an improved version of the $\mathrm{WHO} /$ Rose questionnaire for use in epidemiological surveys. J Clin Epidemiol 1992; 45: 11011109.

16. American Diabetes Association Peripheral ArteriaL Disease in people with diabetes. Diabetes Care. 2003; 26: 3333-3341

17. Hirsch AT, Halverson SL, Treat-Jacobson et al. The Minnesota Regional Peripheral Arterial Disease Screening Program: toward a definition of community standards of care. Vasc. Med. 2001; 6: 87-96

18. Criqui MH, Fronek A, Klauber M, et al. The sensitivity, specificity and predictive value of traditional clinical evaluation of peripheral arterial disease; results from non-invasive testing in a defined population. Circulation. 1985; 71:516-522

19. Holland-Letz T, Endres HG, Biedermann S, et al. Reproducibility and reliability of the ankle-brachial index as assessed by vascular experts, family physicians and nurses. Vasc Med 2007; 12:105-112.

20. Sprynger M, Fassotte C, Verhaeghe R. The anklebrachial pressure index and a standardized questionnaire are easy and useful tools to detect peripheral arterial disease in non-claudicating patients at high risk. Int Angiol 207; 26: 239-244

21. Aronow WS, Fleg JL, Pepine CJ, et al. ACCF/AHA 2011 Expert Consensus Document on Hypertension in the Elderly. A Report of the American College of Cardiology Foundation Task Force on Clinical Expert Consensus Documents. Developed in collaboration with the American Academy of Neurology, American Geriatrics Society, American Society for Preventive Cardiology, American Society for Hypertension, American Society of Nephrology, Association of Black Cardiologists, and European Society of Hypertension. J Am Coll Cardiol 2011; 57: 2037-2114.
22. Aronow WS, Ahn C. Frequency of new coronary events in older persons with peripheral arterial disease and serum low-density lipoprotein cholesterol $\geq 125 \mathrm{mg} / \mathrm{dl}$ treated with statins versus no lipidlowering drug. Am J Cardiol 2002; 90: 789-791

23. Vidula H, Tian L, Liu K, et al. Comparison of effects of statin use on mortality in patients with peripheral arterial disease with versus without elevated C-reactive protein and D-dimer levels. Am $J$ Cardiol 2010; 105: 1348-1352

24. Heart Protection Study Collaborative Group. Randomized trial of the effects of cholesterol-lowering with simvastatin on peripheral vascular and other major vascular oputcomes in 20,536 people with peripheral arterial disease and other high-risk conditions. J Vasc Surg 2007; 45: 645-654.

25. Aronow WS, Ahn C. Frequency of congestive heart failure in older persons with prior myocardial infarction and serum low-density lipoprotein cholesterol $\geq 125 \mathrm{mg} / \mathrm{dl}$ treated with statins versus no lipid-lowering drug. Am J Cardiol 2002; 90: 147-149

26. Owusu-Dabo E, Lewis S, McNeill A, Gilmore A, Britton J. Smoking uptake and prevalence in Ghana. Tobacco Control. 2009; 18:365-370. doi:10.1136/tc.2009.030635].

27. Gardner AW, Katzel LI, Sorkin JD, et al. Exercise rehabilitation improves functional outcomes and peripheral circulation in patients with intermittent claudication: a randomized controlled trial. $J \mathrm{Am}$ Geriatr Soc. 2001; 49(6):755-762

28. Wang J, Zhou S, Bronks R, et al. Effects of supervised treadmill walking training on calf muscle capillarization in patients with intermittent claudication. Angiology. 2009;60(1):36-41.

29. Murphy TP, Cutlip DE, Regensteiner JG, et al. Supervised exercise versus primary stenting for claudication resulting from aortoiliac peripheral arterial disease: six-month outcomes from the claudication: exercise versus endoluminal revascularization (CLEVER) study. Circulation. 2012; 125(1):130139.

30. Gardner AW, Poehlman ET. Exercise rehabilitation programs for the treatment of claudication pain. A metaanalysis. JAMA 1995; 274: 975-980.

31. Hirsch AT, Haskal ZJ, Hertzer NR, et al. ACC/AHA 2005 Practice Guidelines for the management of patients with peripheral arterial disease (lower extremity, renal, mesenteric, and abdominal aortic): executive summary. Circulation 2006; 113: 1474-1547.

32. Hiatt WR, Wolfel EE, Meier RH, Regensteiner JG. Superiority of treadmill walking exercise versus strength training for patients with peripheral arterial disease. Implications for the mechanism of the training response. Circulation 1994; 90: 1866-1874. 
33. Perera GB, Lyden SP. Current trends lower extremity revascularization. Surg Clin North Am 2007, 87: 1135-1147

34. Pearce BJ, Toursarkissian B. The current role of endovascular intervention in the management of diabetic peripheral arterial disease. Diabetic Foot \& Ankle 2012, 3:18977

35. Weitz JI, Byrne J, Clagett GP, et al. Diagnosis and treatment of chronic arterial insufficiency of the lower extremities: a critical review. Circulation 1996; 94: 3026-3049.
36. Comerota AJ. Endovascular and surgical revascularization for patients with intermittent claudication. Am J Cardiol 2001; 87 (Suppl): 34D-43D.

37. Nayak D, Aronow WS. Effect of an ongoing educational program on the use of antiplatelet drugs, beta blockers, angiotensin-converting enzyme inhibitors, and lipid lowering drugs in patients with coronary artery disease seen in an academic cardiology clinic. Cardiol Rev 2005; 13: 95-97. 